\title{
ARTERIAL THICKENING IN OLD AGE
}

\author{
BY \\ TREVOR H. HOWELL \\ From the Royal Hospital, Chelsea \\ Received May 10, 1945
}

The pathology of arteriosclerosis has been much studied in recent years: but the clinical aspects have had little attention. A small book on diagnosis written by Parkinson in 1898 had more space devoted to examination of the arteries than Saville's "Clinical Medicine" of 1939, which has six times the number of pages. Even Cowdry's symposium on arteriosclerosis does not say much on the clinical aspects of arterial thickening. In fact, Sydenstricker there quotes the statistics of the Life Extension Institute of America, and gives the final age group as " sixty or over." It is only in this and the following decades that the state of the arteries assumes real importance. It would seem, therefore, that there is a lack of reliable information about the arterial thickening of later life, at least on the clinical side. Apart from a note by Lansbury and Brown about the importance of calcification and the figures of Sydenstricker, there is little in recent papers which bears on this point. The present paper deals with the findings on examination of Chelsea pensioners and offers a new method of classifying arterial thickening in old persons.

\section{STANDARDS}

This investigation was one of a series designed to provide data about the normal variations of temperature, pulse rate, blood pressure, arterial thickening, etc., in healthy old persons. Chelsea pensioners, of whom 341 were examined, proved excellent material for this purpose. All were veterans of the old professional British regular army and therefore had been fit, healthy men accustomed to exertion in their early manhood. Before coming to the Royal Hospital, they had to be medically certified as being fit to perform light duties-sick men not being admitted. In addition to being selected material, these men lived a regular life under supervision and medical observation.

Every man in the series under review was given a physical examination, in the course of which his radial, brachial, temporal, and femoral arteries on both side of the body were palpated. The vessels were compressed by the index and ring fingers while the third finger felt the artery and rolled it under the finger-tip. After this, the fingers were rubbed up and down the course of the vessel longitudinally to ascertain the amount of tortuousity or calcification present, as well as the amount of thickening of the wall.

Generally speaking, the brachial arteries showed thickening of their walls more markedly than any others, but calcification was found only in the radial and temporal arteries. Tortuousity was common in the temporal vessels, but also occurred in radials and brachials. In the last two it was associated with at least moderate thickening, which was not the case as regards the temporals. The brachial tortuousity took the form of small segments of a large curve, but the radial curves were often large segments of a small one. Brachial tortuousity was often accompanied by radial calcification. In fact, one group (IV) in the suggested classification was composed of cases showing brachial thickening and tortuousity with slight or patchy calcification of both radials. Examination of the femoral artery gave little additional information as a rule. The fundus oculi was not examined, a previous survey having shown little correlation between the opthalmoscopic picture and the peripheral general arterial state. (Howell, Brit. Heart J., 1942). For classification purposes, the final impression after examining and, if necessary, re-examining the accessible arteries was taken as guide. A few cases were hard to decide, but these mostly had some calcification of one radial with only slight 
thickening elsewhere. The classification of arterial changes by age groups is shown in Table I.

TABLE I

Arterial Thickening in Patients divided according to Age

\begin{tabular}{|c|c|c|c|c|c|c|c|c|c|}
\hline \multirow{2}{*}{\multicolumn{4}{|c|}{ Age period }} & \multicolumn{6}{|c|}{ Group distribution of each age period in percentages of each age period } \\
\hline & & & & \multirow[b]{2}{*}{$\begin{array}{r}\text { Total } \\
3 \\
11 \\
37 \\
146 \\
81 \\
40 \\
20 \\
3\end{array}$} & \multirow[b]{2}{*}{$\begin{array}{c}\text { No. I } \\
100 \\
27 \\
27 \\
19 \\
8 \\
5 \\
- \\
-\end{array}$} & \multirow[b]{2}{*}{$\begin{array}{c}\text { No. II } \\
54 \\
19 \\
21 \\
13 \\
10 \\
10 \\
-\end{array}$} & \multirow[b]{2}{*}{$\begin{array}{c}\text { No. III } \\
-19 \\
43 \\
48 \\
57 \\
43 \\
40 \\
-\end{array}$} & \multirow[b]{2}{*}{$\begin{array}{c}\text { No. IV } \\
- \\
- \\
8 \\
8 \\
15 \\
30 \\
25 \\
-\end{array}$} & \multirow[b]{2}{*}{$\begin{array}{r}\text { No. V } \\
- \\
3 \\
4 \\
7 \\
12 \\
25 \\
100\end{array}$} \\
\hline $\begin{array}{l}55-59 \\
60-64 \\
65-69 \\
70-74 \\
75-79 \\
80-84 \\
85-89 \\
90-95\end{array}$ & $\begin{array}{l}\ldots \\
\ldots \\
\ldots \\
\ldots \\
\ldots \\
\ldots\end{array}$ & $\begin{array}{l}. \\
\ldots \\
\ldots \\
\ldots \\
\ldots \\
\ldots \\
.\end{array}$ & $\begin{array}{l}\ldots \\
\ldots \\
\ldots \\
\ldots \\
\ldots \\
\ldots \\
\ldots \\
\ldots\end{array}$ & & & & & & \\
\hline & & & & 341 & & & & & \\
\hline
\end{tabular}

\section{Classification}

Five groups of men were found on analysis of the 341 examined. The first consisted of those without any obvious arterial thickening. The second was composed of those in whom the thickening was slight. The third group, classified as having moderate thickening, had arteries that were easily palpable. The fourth showed thickening of all the arteries examined, with tortuousity in some of them, often accompanied by slight or patchy calcification of the radials. The fifth group had marked calcification present. As may be seen in Table I, there tended to be a steady drift from group I to group $\mathrm{V}$ as the age increased. One man, not included in this series, was watched over a period of five years. At the beginning of this time, although his fundus oculi showed arterial changes, there was only minimal thickening of his limb vessels. At the end of the period, he was in group III. Other men observed over a period of three years, passed from group II to group III, from III to IV, from IV to V, and even from III to V during this time. This occurred in ten patients, while ten others remained in the same state as at the beginning of the period. No cases were found to proceed from harder to softer arteries, or from tortuousity to straight vessels, but two doubtful cases were finally settled in group IV, rather than group V.

The first group, those without arterial thickening, was composed of 53 men (Table II), whose ages ranged from fifty-six to eighty-four. Many of the older members did not look their age nor behave in a senile fashion. A few were obese, so that palpation of their vessels was not easy. The vast majority in this group were fit and healthy, only two having physical signs of disease; one had a Plummer-Vinson syndrome, the other had high blood pressure with auricular fibrillation and a large heart.

TABLE II

Age of Patients divided according to Group of Arterial Thickening

\begin{tabular}{|c|c|c|c|c|c|c|c|c|}
\hline \multirow{2}{*}{\multicolumn{3}{|c|}{ Arterial group }} & \multicolumn{4}{|c|}{ Percentage of each arterial group in each age period } & \multirow{2}{*}{ Total } & \multirow{2}{*}{ Percentage } \\
\hline & & & $55-65$ & $65-75$ & $75-85$ & $85-95$ & & \\
\hline \multirow[t]{2}{*}{$\begin{array}{r}\text { I } \\
\text { II } \\
\text { III } \\
\text { IV } \\
\text { V }\end{array}$} & \multirow[t]{2}{*}{$\begin{array}{l}\ldots \\
\cdots \\
\ldots \\
.\end{array}$} & \multirow[t]{2}{*}{$\begin{array}{l}\ldots \\
\ldots \\
\ldots \\
\ldots\end{array}$} & \multirow[t]{2}{*}{$\begin{array}{r}12 \\
10 \\
1 \\
-\end{array}$} & \multirow[t]{2}{*}{$\begin{array}{l}71 \\
65 \\
54 \\
34 \\
24\end{array}$} & \multirow[t]{2}{*}{$\begin{array}{l}17 \\
22 \\
39 \\
54 \\
44\end{array}$} & \multirow[t]{2}{*}{$\begin{array}{r}-3 \\
5 \\
12 \\
32\end{array}$} & $\begin{array}{r}53 \\
60 \\
159 \\
44 \\
25\end{array}$ & $\begin{array}{r}15 \cdot 5 \\
17 \cdot 8 \\
46 \cdot 2 \\
12.9 \\
7 \cdot 6\end{array}$ \\
\hline & & & & & & & 341 & $100 \cdot 0$ \\
\hline
\end{tabular}

The second group of pensioners comprised 60 men between sixty and eight-five of age. In these cases the arteries could be felt like a thin tape when the vessels were compressed. Any with vessels more prominent than this on palpation were placed in the next group, if more than one artery was affected. The brachials were easier to feel than the radials, while the temporals often had tortuousity, but nevertheless remained soft. The age distribution was similar to that of the preceding class, except that a larger number of men over seventy-five 
was met. Only three of the men had a medical history of any significance, two having past cerebral thromboses and one congestive heart failure following hypertension.

The third group was by far the largest. It contained the men with arteries that were thickened, but not tortuous nor calcified. The degree of thickening varied from a sensation as of a soft cord under the skin to that of a tough leathery tube. There were probably several sub-groups not yet clearly defined. The number of cases totalled 159 , nearly half the number of men examined. Over 40 per cent of all men between sixty-five and eighty-nine came into this class, but only two were under sixty-five. A great variety of physical states was met in this category of pensioner, varying from perfectly fit healthy old men to those with chronic bronchitis, with old hemiplegia, or with cerebral arteriosclerosis. The younger members of the group were not more clearly healthy nor more conspicuously unfit than their seniors. For this reason it is hard to draw any conclusions about the significance of this degree of arterial change.

The fourth group was composed of 44 pensioners whose ages varied from sixty-six to eighty-nine. More than half the men were over eighty. As the distinguishing feature of the group was the possession of arteries that were thickened and tortuous, with or without slight calcification: it suggests that extreme age, tortuousity, and calcification are connected in some way. The calcification varied from a few hard beads to be felt on rubbing up and down the vessel to irregular hardened areas several millimetres in length. Ten men ( 23 per cent) in the group were noted as completely fit. The others had signs of past disease or of degeneration such as sclerotic cardiac murmurs, marked effort dyspnœa, hemiplegia, and so on. Some of the pensioners who needed recurrent admissions to the infirmary of the hospital were found here. On the whole, the older men were healthier than the younger ones with this group.

The fifth group included 25 pensioners all of whom showed marked calcification of their radial arteries as well as thickening of their palpable arteries. Their ages ranged from sixtysix to ninety-one, three quarters of them being over seventy-five. All three men over ninety were in this group; but the oldest pensioner in the hospital, aged ninety-six, who was not included in this series, would have been placed in the fourth group. Twelve of the men were relatively healthy and able to get about in comfort. The remainder were more or less infirm, six having only recently returned from the infirmary to which they had been on account of advanced cardio-vascular disease requiring treatment.

\section{Blood Pressure}

Each man had a blood pressure reading taken as part of his examination. While a single reading is not satisfactory, it was noted that, in cases where the usual figures for a man were known, there was no deviation from what had been expected. 79 per cent of the pensioners had systolic readings over $160 \mathrm{~mm}$. This was higher than the 50 per cent with similar levels found in 120 successive admissions to the infirmary in 1941-42. The present series, however, deals with the healthy men and not the sick. It was found that in group I, 59 per cent had a systolic pressure over $160 \mathrm{~mm}$; in group II, 53 per cent; in group III it rose to 80 per cent; in group IV to 84 per cent; and in group V to 96 per cent. The high percentage in the last three groups is noteworthy. About a quarter ( 24.6 per cent) of the men had their

TABLE III.-SyStolic Figures OVER 200 MM.

\begin{tabular}{|c|c|c|c|c|c|c|}
\hline \multirow{2}{*}{ Arterial group } & \multicolumn{4}{|c|}{ Age periods } & \multirow{2}{*}{ Total } & \multirow{2}{*}{$\begin{array}{l}\text { Percentage of each } \\
\text { group with B.P. } \\
\text { over } 200\end{array}$} \\
\hline & $55-65$ & $65-75$ & $75-85$ & $85-95$ & & \\
\hline $\begin{aligned} & \text { II } \\
& \text { II } \ldots \\
& \text { II } \ldots \\
& \text { V } \cdots \\
& \text { All groups } \\
& \text { Percentage of each } \\
& \text { age period with } \\
& \text { B.P. over 200 }\end{aligned}$ & $\begin{array}{l}0 \\
0 \\
1 \\
0 \\
0 \\
1 \\
\\
7\end{array}$ & $\begin{array}{r}5 \\
2 \\
24 \\
5 \\
3 \\
39 \\
\\
21\end{array}$ & $\begin{array}{r}1 \\
4 \\
15 \\
9 \\
6 \\
65 \\
35 \\
\\
29\end{array}$ & $\begin{array}{r}0 \\
1 \\
4 \\
2 \\
4 \\
11 \\
\\
50\end{array}$ & $\begin{array}{r}6 \\
7 \\
44 \\
16 \\
13 \\
86 \\
\\
25\end{array}$ & $\begin{array}{l}11 \\
12 \\
29 \\
37 \\
52 \\
25\end{array}$ \\
\hline
\end{tabular}


systolic pressure over $200 \mathrm{~mm}$. In these pensioners, the diastolic figures varied from $100 \mathrm{~mm}$. to $140 \mathrm{~mm}$., only a small number being over $120 \mathrm{~mm}$. Out of a total of 86 patients, 6 were in group I, 7 in group II, 44 in group III, 16 in group IV and 13 in group V. Only 1 was under sixty-five, 39 were between sixty-five and seventy-five, 35 between seventy-five and eighty-five and 11 between eighty-five and ninety-five. These results are shown in Table III.

As may be seen from Tables III and IV, the percentage of men with a systolic figure over $200 \mathrm{~mm}$., rises with age, but later than the percentage of all the men with raised systolic pressure. From these figures it seems that both advancing age and increasingly thickened arteries were associated with a higher blood pressure.

TABLE IV

Arteriosclerosis and Raised Blood Pressure (over 160)

\begin{tabular}{|c|c|c|c|c|c|c|}
\hline \multirow{2}{*}{ Arterial group } & \multicolumn{4}{|c|}{ Age periods } & \multirow{2}{*}{ Total } & \multirow{2}{*}{$\begin{array}{l}\text { Percentage of each } \\
\text { group with B.P. } \\
\text { over } 160\end{array}$} \\
\hline & $55-65$ & $65-75$ & $75-85$ & $85-95$ & & \\
\hline 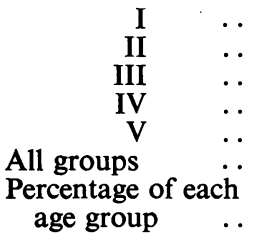 & $\begin{array}{r}1 \\
2 \\
1 \\
0 \\
0 \\
4 \\
28\end{array}$ & $\begin{array}{r}23 \\
19 \\
64 \\
13 \\
6 \\
125 \\
68\end{array}$ & $\begin{array}{r}7 \\
11 \\
54 \\
20 \\
10 \\
102 \\
84\end{array}$ & $\begin{array}{r}0 \\
2 \\
8 \\
4 \\
8 \\
22 \\
\\
95\end{array}$ & $\begin{array}{r}31 \\
34 \\
127 \\
37 \\
24 \\
253 \\
77\end{array}$ & $\begin{array}{l}59 \\
53 \\
80 \\
84 \\
96 \\
77\end{array}$ \\
\hline
\end{tabular}

\section{Discussion}

The first impression arising from the examination of these cases was that the usual procedure of compressing the radial artery at the wrist was not a sufficient guide to the state of the vessels. In some patients there would be neither tortuousity nor calcification in the segment of the artery palpated, and this might give rise to a false estimate of the degree of arterial change present. Examination of both radials and brachials was the minimum which could be of any real value. Also the process of rubbing the fingers up and down the course of the artery gave a lot of information about its condition that was not elicited in any other way. This was especially true when the patient was obese and the vessel not easy to feel. Next, it was found that while there was truth in the general rule that thickening, tortuousity, and calcification grew more frequent with advancing years, yet many exceptions could be met. In fact, there seemed to be a number of men in the eighties whose arteries would not have been abnormal for those twenty years their junior. The group III cases were a real problem. While the proportion of pensioners with raised blood pressure was much higher than in the two preceding groups, and a history of past vascular lesions was not uncommon, yet a number of the men in this group were known to be much more active in body and mind than others of their age. Even among those between sixty and seventy there were about equal numbers of prematurely decrepit veterans and men who were taken for fifteen years less than their true age. The sensation of moderate thickening of an artery covers so many gradations which it is difficult to distinguish that, as stated before, there are probably several sub-groups. As expected, tortuousity and calcification were usual in pensioners over eighty. The ability to express these findings in a simple classification indicates that it has some advantages over the "slight," "moderate," "marked" thickening and "calcified arteries" which are the terms commonly employed at present.

\section{SUMMARY}

When the arteries of 341 Chelsea pensioners were examined, it was found that they could be classified into five groups, each with distinct characters; and probably successive stages of sclerotic change. An improved method of clinical examination of arteries is described and its advantages pointed out. 